2006 ERSD Annual Report

DOE-BER Environmental Remediation Sciences Project \# 1028037

\title{
Geochemical \& Physical Aquifer Property Heterogeneity: A Multiscale Sedimentologic Approach to Reactive Solute Transport
}

\author{
PI: Chris Murray ${ }^{1}$ \\ Co-PIs: Richelle Allen-King ${ }^{2}$ and Gary Weissmann ${ }^{3}$ \\ Pacific Northwest National Laboratory, Richland, $W A^{1}$ \\ Univ. at Buffalo (SUNY) ${ }^{2}$ \\ Univ. of New Mexico ${ }^{3}$
}

\section{Research Objective}

This project is testing the hypothesis that sedimentary lithofacies determine the geochemical and physical hydrologic properties that control reactive solute transport (Figure 1). We are testing that hypothesis for one site, a portion of the saturated zone at the Hanford Site (Ringold Formation), and for a model solute, carbon tetrachloride (CT). The representative geochemical and physical aquifer properties selected for quantification in the proposed project are the properties that control CT transport: hydraulic conductivity $(\mathrm{K})$ and reactivity (sorption distribution coefficient, $\mathrm{K}_{\mathrm{d}}$, and anaerobic transformation rate constant, $\mathrm{k}_{\mathrm{n}}$ ). We are combining observations at outcrop analog sites (to measure lithofacies dimensions and statistical relations) with measurements from archived and fresh core samples (for geochemical experiments and to provide additional constraint to the stratigraphic model) from the Ringold Formation to place local-scale lithofacies successions, and their distinct hydrologic property distributions, into the basinal context, thus allowing us to estimate the spatial distributions of properties that control reactive solute transport in the subsurface. The objectives of the proposed project are to:

- Determine the significance of lithofacies in explaining the variance of $\mathrm{K}$ and reactivity to CT, indicated by $\mathrm{K}_{\mathrm{d}}$, for the Ringold Formation through intensive sampling and analysis, and rigorous statistical testing. We will also measure $\mathrm{k}_{\mathrm{n}}$ and conduct detailed characterization of selected samples representative of saturated Ringold Formation units to characterize differences in transformation rate and the controlling geochemical properties;

- Develop a stratigraphic framework for the study site, built on our measurements of lithofacies geometries and spatial distributions, and use this to model the distribution of lithofacies at the study site through application of transition probability geostatistics;

- Combine the simulated lithofacies spatial distributions and the observed $\mathrm{K}, \mathrm{K}_{\mathrm{d}}$ and $\mathrm{k}_{\mathrm{n}}$ for each lithofacies to create numerical models of the spatial distributions of reactive transport properties for a portion of the CT contaminated site; and

- Use the improved numerical model of the site in preliminary reactive transport simulations to demonstrate its effects on our understanding of CT fate and transport in the Ringold Formation. 
Thus, the project will provide basic scientific information on the lithofacies control of sediment properties controlling reactive solute transport as well as providing valuable data and models that will help address a major reactive transport problem at a DOE site.

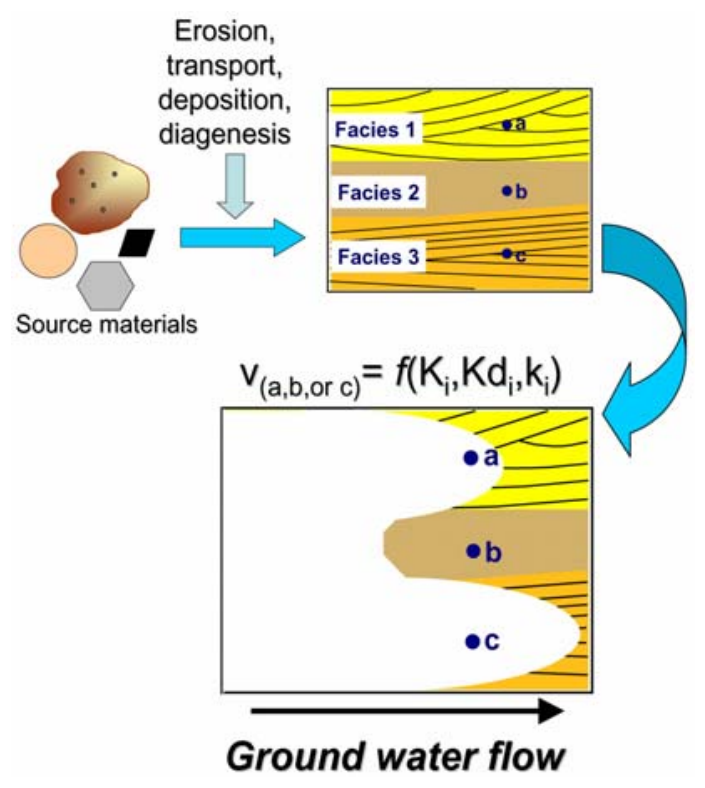

Figure 1. Conceptual model for lithofacies control on reactive transport.

\section{Research Progress and Implications}

This report summarizes work completed after 6 months of a 3 year project. During the first field season, investigators from the University of New Mexico (UNM) and Pacific Northwest National Laboratory (PNNL) collaborated on field studies of outcrops of the Ringold Formation. The CT plume in Hanford's 200 West Area occurs within that unit, which is exposed along the White Bluffs, $22 \mathrm{~km}$ east of the CT plume study area. The focus of the field studies was the examination of grain size, sedimentary structures, and preliminary composition (through hand-sample identification) within the clast supported gravel units of the Ringold.

Investigators from UNM and PNNL also collaborated on the description and laboratory analysis of available core. Approximately 1065 meters of core from 6 wells were examined during this effort. During the field and laboratory studies, investigators noted and described the widespread occurrence of two types of geologic features that may have major implications for the transport of CT through the aquifer: iron-rich coatings on the sediments (Figure 2) and carbonaceous matter in the sediments (Figure 3 ), including both leaf fragments and woody detritus. The spatial distribution of iron staining and carbonaceous matter are likely to be influenced by the geologic processes that controlled the initial deposition of the sediments and their later diagenesis. The geologic controls on these features could lead to lithofacies control of the reactive transport of CT in the 200 West Area aquifer. 


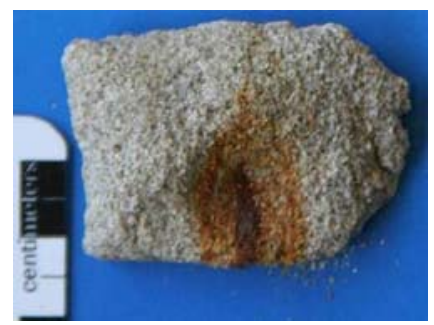

Figure 2. Widespread iron oxide staining was observed in cores from the Ringold Formation.
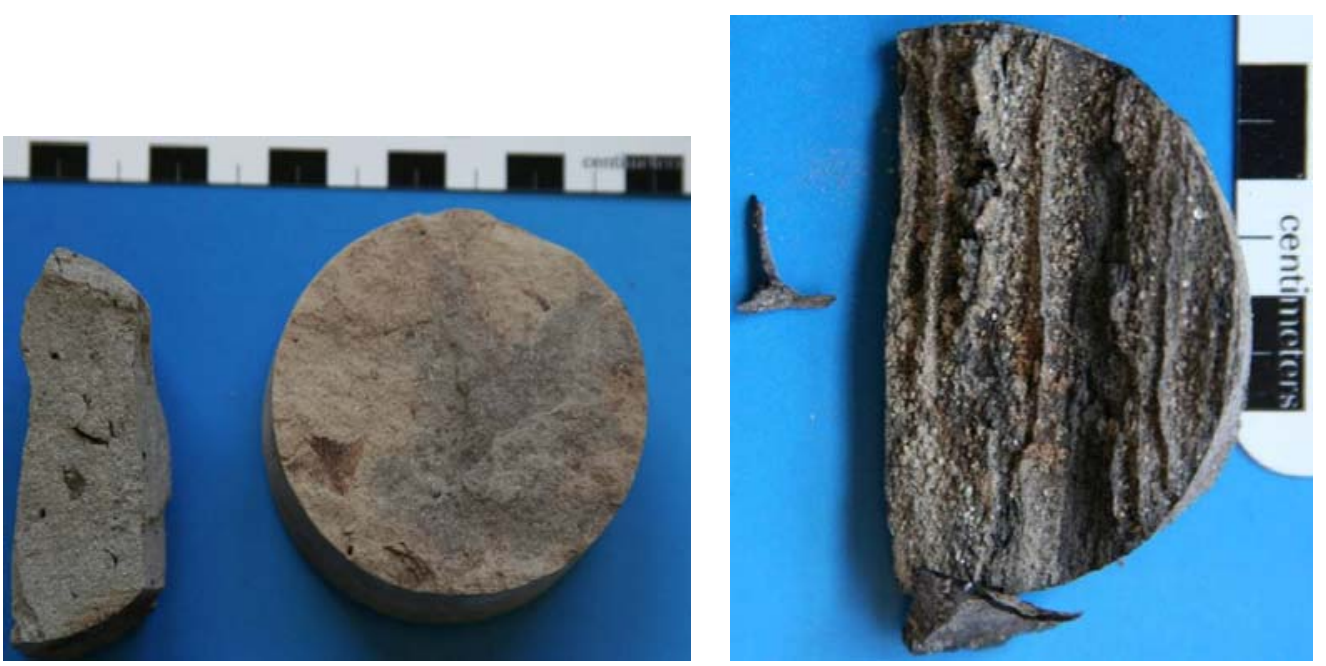

Figure 3. Leaf fragments, woody detritus, and other carbonaceous matter were described and sampled in cores from the Ringold Formation.

Investigators from the University of Buffalo (UB) have performed initial experiments to evaluate the experimental apparatus and design for analysis of the reactivity of sediments in the different lithofacies. Steps have been taken by investigators from UB and PNNL to identify the locations of archived sample and core material that will be used for experiments to determine the lithofacies dependence of CT sorption in the aquifer. In addition, the investigators from UB and PNNL are working with personnel from Fluor Hanford to identify the upcoming drilling locations planned in the 200 West Area that have the best potential for providing useful fresh core material needed for experimental determination of the factors controlling abiotic transformation of $\mathrm{CT}$ in the aquifer.

In addition to collaborating on the studies above, investigators from PNNL have developed a protocol for evaluation and validation of geostatistical software and analyses that will be employed for generating the numerical grids of physical and chemical aquifer properties.

\section{Planned Activities}

Task 1. Evaluate and measure lithofacies/facies assemblage distributions in outcrop and core and develop framework (Task lead: UNM, support from PNNL) 
Task 2. Characterize distributions of hydraulic conductivity and sorption distribution coefficient by lithofacies and statistically test differences (Task lead: UB, support from PNNL and UNM)

Task 3.Characterize sediment properties to elucidate controls on sorption (Task lead: UB) Task 4. Measure abiotic CT transformation rate and geochemically characterize representative lithofacies samples (Task lead: UB)

Task 5. Create a stochastic model of the sedimentary architecture (Task lead: UNM) Task 6. Create a stratigraphically-based model of physical and geochemical parameter distribution for a limited sample domain for the aquifer (Task lead: PNNL) Task 7. Compare transport simulation results for the stratigraphically based system to transport through alternative model systems. (Task lead: PNNL)

- Field measurements in support of Task 1 were initiated during summer 2006 and will be completed during summer 2007. Task 5, which depends on Task 1, began in Fall 2006 using the data set compiled during the prior summer. The second field season (2007) will be used for QA/QC checking and additional outcrop/core mapping based on preliminary simulations. Task 5 will be completed during Fall 2007 and will be followed by manuscript preparation.

- Task 2 began in Fall 2006 with method refinement, compilation of existing grain size and hydraulic conductivity data, and identification of archived core samples. Fresh samples for both Tasks 2 and 4 will be obtained during winter 2007. Additional samples for the sorption heterogeneity measurements may be collected during Summer 2007. Grain-size distribution and K measurements will be completed by fall 2007. Sorption measurements on the representative lithofacies samples will be completed by fall 2007. Anaerobic transformation and sediment characterization experiments will be conducted through fall 2007. Thus, the geochemical, physical and sedimentological attributes of the aquifer will be measured and compiled during fall 2007 in preparation for the modeling work. Any additional sediment characterization required for Task 4 as well as manuscript preparation describing these topics will be conducted during spring 2008.

- Task 3 will be initiated in fall 2007 and will be completed by the end of summer 2008. Manuscript preparation for the results of this task will take place during fall 2008.

- Task 6 will be initiated in fall 2007 with geostatistical analysis of the grain size and hydraulic conductivity data and continue when reactive transport properties are available. Initial lithofacies controlled simulations of aquifer properties will be generated in fall 2007 using preliminary lithofacies simulations generated for Task 5. Completion of the geostatistical property simulations for Task 5 will occur by the spring of 2008 , followed by manuscript preparation during the summer and fall of 2008.

- Task 7 will be initiated in winter 2007, identifying reaction network and parameters needed for flow and transport model (collaboration of PNNL, UB, and UNM); developing and adapting the required transport codes; and identifying boundary conditions from the sitewide groundwater model. Preliminary transport runs will occur in the fall of 2007, with completion of Task 7 by the summer of 2008, followed by manuscript preparation during the fall of 2008 . 


\section{Information Access}

Presentations of the preliminary results of the project have been provided at two DOE meetings, the Environmental Remediation Sciences Program (ERSP) Workshop, Idaho Falls, ID on June 12, 2006, and the ERSP Field Investigators Workshop, Oak Ridge, TN on October 25, 2006. 